\title{
Diagnose visual de potássio e ferro no crescimento inicial de mudas de Physalis ixocarpa $\mathbf{L}$.
}

\author{
Bruno Paulo Moschini ${ }^{1 *}$, Nicole Colombari Cheng¹, Diego Faustolo Alves Bispo르, Jefferson Luiz \\ Antunes Santos ${ }^{1}$, Carlos Enrrik Pedrosa, Pedro Maranha Peche ${ }^{1}$
}

\begin{abstract}
RESUMO: O cultivo de fisalis (Physalis ixocarpa L.) apresenta grande potencial econômico e está sendo incorporado aos plantios do grupo de pequenas frutas no Brasil. Entretanto, ainda há pouco detalhamento das necessidades nutricionais relacionados a essa cultura. Objetivou-se avaliar o desenvolvimento vegetativo e sintomas de deficiência e/ou toxicidade nutricional da fisalis em diferentes concentrações de potássio (K) e ferro (Fe) em solução nutritiva. O experimento foi conduzido em casa de vegetação e o delineamento experimental utilizado foi o inteiramente casualizado com seis repetições e sete tratamentos: solução nutritiva de Hoagland, Arnon completa (controle) e as soluções nutritivas com concentrações de 50, 150 e 200\% de K e 50, 150 e 200\% de Fe. Avaliou-se o diâmetro caulinar, altura das plantas, número de folhas emitidas, valor SPAD e a produção de massa seca da parte aérea (PA), raízes (R) e total $(\mathrm{PA}+\mathrm{R})$, bem como a relação R/PA. O Fe mostrou ser um importante nutriente para a fisalis, pois limitou o crescimento das mudas quando cultivado em solução nutritiva com $50 \%$ de Fe. O crescimento e o desenvolvimento das mudas foram maiores nas plantas cultivadas em solução com concentração de $150 \%$ de Fe, entretanto, não houve diferenças entre a produção de massa seca entre as concentrações avaliadas de K.
\end{abstract}

Palavras-chave: fisalis, solução nutritiva, deficiência nutricional, diagnose visual.

\section{Visual diagnosis of potassium and iron on initial growth of Physalis ixocarpa L. seedlings}

\begin{abstract}
The cultivation of physalis (Physalis ixocarpa L.) presents great economic potential and is being incorporated into the plantations of the small fruit group in Brazil. However, there is still little detail on the nutritional needs related to this crop. The objective of this study was to evaluate the vegetative development and nutrient disorders of deficiency and toxicity of culture physalis under different concentrations of potassium $(\mathrm{K})$ and iron $(\mathrm{Fe})$ in nutrient solution. The experiment was conducted in a greenhouse and the experimental design was a completely randomized design with six replicates and seven treatments: nutrient solution of Hoagland, Arnon complete (control) and nutrient solutions with concentrations of 50, 150 and $200 \%$ of $\mathrm{K}$ and 50, 150 and $200 \%$ of Fe. Leaf diameter, plant height, number of leaves emitted, SPAD value and dry mass production in shoot (PA), root (R) and total (PA $+\mathrm{R})$ were evaluated, as well as the R / PA ratio. Fe proved to be an important nutrient for fisalis, as its limited seedling growth when grown in a 50\% Fe nutrient solution. The growth and development of the seedlings were higher in plants grown in a $150 \% \mathrm{Fe}$ solution. however, there were no differences between dry mass production between the evaluated $\mathrm{K}$ concentrations.
\end{abstract}

Keywords: golden berry, nutrient solution, nutritional deficiency, visual diagnosis.

\section{INTRODUÇÃO}

A fisalis é uma planta da família das solanáceas e do gênero Physalis L., compreendendo mais de cem espécies conhecidas. Os centros de origem e diversificação da fisalis, se encontram na região dos Andes, principalmente na Colômbia, Peru e Equador, possuindo variedades cultivadas na América, Europa e Ásia (RUFATO et al., 2012). Entre elas podem ser citadas a $P$. angulata L., $P$. peruviana, $P$. pubescens, $P$. primorosa, $P$. ixocarpa e P. philadelphia (THOMÉ, OSAKI, 2010).

Inserido no grupo das pequenas frutas, o gênero Physalis L., é muito difundido no mercado internacional pelo seu sabor, valor nutricional (Vitamina A, C, fósforo, ferro, flavonoides, alcaloides, fitoesteroides, carotenoides, compostos bioativos, entre outros), características medicinais e nutracêuticos (SALGADO, ARANA, 2013; MAMEDOV et al., 2017; MOKHTAR et al., 2018). No Brasil, o cultivo da fisalis ainda é recente e pouco difundido, porém a cultura tem se tornado uma ótima alternativa de cultivo, especialmente pelo seu alto valor comercial e produtivo (MUNIZ et al., 2014; PONCE et al., 2016).

Com o mercado em expansão, são necessários novos estudos para desenvolver tecnologias mais rentáveis ao cultivo da fisalis, bem como caracterizar o crescimento e o desenvolvimento das plantas em condições específicas de clima, solo e manejos dessa cultura (MUNIZ et al., 2015). Dessa forma, estudos sobre a nutrição da Physalis ssp.

Recebido em 21/05/2019; Aceito para publicação em 10/12/2019

${ }^{1}$ Universidade de São Paulo

*E-mail: bruno_moschini@ @otmail.com 
ainda são escassos, existindo poucos parâmetros para a recomendação da adubação, a qual é realizada com base em dados de pesquisa obtidos de outras regiões ou na demanda nutricional da cultura do tomateiro, por se tratar de uma planta da família das solanáceas (IANCKIEVICZL et al., 2013). As recomendações baseadas em outras regiões podem gerar resultados insatisfatórios e inconclusivos em termos nutricionais, resultando em menor qualidade de frutos e menores produtividades (PEREIRA, 2008).

Os aspectos nutricionais dessa planta devem ser mais bem estudados, quantificando assim suas exigências e, consequentemente, seu crescimento, tornando-se viável determinar o momento mais adequado para iniciar o cultivo, a adubação e os tratos culturais para obtenção de melhores produtividades (MOSCHINI et al., 2018). O estudo sobre o crescimento e desenvolvimento das plantas é de suma importância para o manejo da fisalis e para a observação da sua adaptação às condições de clima e solo em cada região na qual for cultivada, como, também, para avaliar a capacidade produtiva da planta levando em consideração diversas variáveis, como a nutrição mineral das plantas.

Analisar o crescimento e o desenvolvimento vegetativo das plantas está baseado no fato de que cerca de $90 \%$ da massa seca acumulada pelas plantas ao longo do seu crescimento resulta da atividade fotossintética (BENINCASA, 2003). Assim, entende-se que o estudo da massa das culturas e alguns parâmetros de crescimento são importantes ferramentas para se quantificar o crescimento das plantas e, portanto, permitir estabelecer relações entre as mais diferentes variáveis, tais como a fertilização mineral.

Outra ferramenta relevante para conhecer o hábito de crescimento e desenvolvimento vegetativo das plantas e o manejo adequado das culturas é a avaliação do estado nutricional das plantas. Dentre as formas de avaliação do estado nutricional destacase a diagnose visual (MALAVOLTA et al., 1997). Por meio da diagnose visual, é possível caracterizar sintomas que, geralmente, são mais visíveis nas folhas. Os sintomas podem caracterizar deficiência e/ou toxicidade de determinado nutriente, sintomas estes que diferem dependendo da espécie. Para caracterizar esses sintomas com mais segurança e sem a interação com outros fatores, o cultivo em solução nutritiva é uma opção viável (FAQUIN, 2002; BARROSO et al., 2005). Desta maneira, a descrição visual utilizando-se fotografias coloridas, é uma ferramenta de diagnose relevante.

Para o cultivo da fisalis em condições tropicais, não há informações na literatura que caracterizem o aparecimento de deficiência e/ou toxicidade nutricional, bem como descrições da evolução dos sintomas com imagens, principalmente com potássio (K) e ferro $(\mathrm{Fe})$. Acredita-se que o aprimoramento do manejo cultural, com respeito aos aspectos nutricionais da fisalis cultivada em regiões tropicais, possa permitir avanços na produtividade dessa frutífera. Nesse contexto, o objetivo do estudo foi avaliar o desenvolvimento vegetativo inicial e os sintomas de deficiência e/ou toxicidade nutricional da Physalis ixocarpa L. em diferentes concentrações de $\mathrm{K}$ e Fe em solução nutritiva.

\section{MATERIAL E MÉTODOS}

$\mathrm{O}$ experimento foi realizado em casa de vegetação no Departamento de Ciência do Solo da Universidade Federal de Lavras (UFLA) no município de Lavras, Estado de Minas Gerais (21 ${ }^{\circ} 13^{\prime} 34^{\prime}$ ', 44 ${ }^{\circ} 58^{\prime} 45^{\prime}$ ', $943 \mathrm{~m}$ de altitude), entre novembro de 2013 e março de 2014.

As plantas de fisalis (Physalis ixocarpa L.) foram propagadas por sementes em bandeja de poliestireno expandido de 128 células, preenchida com substrato de vermiculita da marca Plantmax ${ }^{\circledR}$, em condições de telado com sombrite de 50\%. Quando as plantas atingiram em média $7,8 \mathrm{~cm}$ de altura e $0,2 \mathrm{~cm}$ de diâmetro caulinar, as mesmas foram colocadas em adaptação à solução nutritiva em casa de vegetação, com solução de Hoagland, Arnon (1950) com 25\% de sua força iônica. Durante o período de adaptação, a força iônica da solução nutritiva foi aumentada gradativamente até atingir $100 \%$. As soluções foram renovadas semanalmente com o intuito de fortalecer o sistema radicular das plantas a partir do aumento da força iônica gradual das soluções, além de impulsionar o crescimento das mudas para uma condição de tamanho ideal.

Após o período de adaptação (30 dias) as plantas alcançaram o tamanho desejado $(15 \mathrm{~cm})$, sendo individualizadas em vasos com capacidade para cinco litros, e então estabelecidos os tratamentos. Os vasos foram pintados, em sua superfície externa, com tinta alumínio e foram colocadas tampas de isopor com um pequeno orifício ao centro, para a fixação das plantas. As plantas foram tutoradas com o auxílio de fitilhos, evitando-se acamamento, devido ao hábito de crescimento ramificado da fisalis cultivada.

O delineamento experimental foi em blocos inteiramente casualizados, com seis repetições e sete tratamentos: solução nutritiva de Hoagland, Arnon (1950) completa (controle) e as soluções nutritivas com concentrações de 50, 150 e $200 \%$ de K e 50 , 150 e $200 \%$ de Fe. As unidades experimentais foram constituídas por uma planta por vaso.

As soluções estoque dos nutrientes foram preparadas com reagentes (p.a.) e água destilada. As soluções nutritivas foram preparadas com água deionizada e, durante o intervalo de renovação das 
soluções, o volume dos vasos foi completado, sempre que necessário, com água deionizada.

Durante todo o experimento (40 dias) o desenvolvimento das plantas foi caracterizado visualmente e os sintomas característicos de deficiência e/ou toxicidade de $\mathrm{K}$ e Fe que pudessem ocorrer pela concentração da solução nutritiva foram fotografados por meio de câmera fotográfica digital com resolução de 13 MP. Foram realizadas duas avaliações no tempo, aos 20 e 40 dias após a individualização das plantas nos vasos com os respectivos tratamentos, com o objetivo de melhor avaliar o desenvolvimento vegetativo inicial da fisalis através da avaliação dos parâmetros de crescimento das plantas, tais como diâmetro caulinar, altura das plantas, número de folhas emitidas e valor SPAD (Soil Plant Analysis Development) (cinco medições em cada folha em três folhas por planta).

Em ambos períodos de avaliação, as plantas foram colhidas, lavadas em água deionizada e subdivididas em parte aérea (PA) e raízes $(\mathrm{R})$. Todo o material foi acondicionado em saco de papel tipo Kraft e seco em estufa com ventilação forçada de ar a $65^{\circ} \mathrm{C}$ até massa constante, conforme descrito por Bryson, Mills (2015). Em seguida, com o auxílio de uma balança de precisão, foi mensurada a produção de massa seca (MS) da PA, R e total (PA+R), bem como a relação R/PA, segundo metodologia proposta por Magalhães (1979).

Os resultados foram submetidos à análise de variância, e havendo significância pelo teste $F$, as médias foram comparadas pelo teste de Tukey a 5\% de probabilidade. Para a realização da análise estatística foi utilizado o programa computacional SISVAR (Ferreira, 2011). Todas as variáveis avaliadas foram apresentadas na forma gráfica em barras verticais com as respectivas barras de erro padrão da média, para tal foi utilizado o software SigmaPlot ${ }^{\circledR}$ (versão 11.0).

\section{RESULTADOS E DISCUSSÕES \\ Parâmetros de crescimento das plantas avaliadas}

$\mathrm{O}$ diâmetro caulinar, crescimento em altura e o número de folhas emitidas da fisalis diferiram ( $p \leq$ $0,05)$ entre as concentrações de $\mathrm{K}$ e Fe na solução nutritiva nas duas avaliações realizadas (Figura 1), indicando que esses nutrientes podem ser considerados fatores limitantes no crescimento e desenvolvimento vegetativo das plantas em algum momento. Os valores SPAD não foi possível observar diferenças a partir da análise de variância entre os tratamentos, em ambas as avaliações realizadas.

Analisando o diâmetro caulinar nas diferentes concentrações de $\mathrm{K}$ e $\mathrm{Fe}$ na fisalis foi possível observar diferenças entres os tratamentos apenas na segunda avaliação realizada. As plantas cultivadas em solução nutritiva com concentração de $150 \%$ de $\mathrm{K}$ e $\mathrm{Fe}$, foram as que apresentaram os maiores diâmetros caulinares, representando valores de 79 e $43 \%$ superior ao tratamento com solução completa. $\mathrm{Na}$ avaliação dos parâmetros de crescimento das plantas, o menor valor de altura das plantas foi atribuído as plantas que foram cultivadas em concentração de $200 \%$ de $\mathrm{Fe}$, com valores de 30 e $10 \%$ inferior ao tratamento com solução completa na primeira e segunda avaliação, respectivamente. Em relação ao número de folhas emitidas na primeira avaliação, os maiores valores foram obtidos para as plantas cultivadas em concentração de $150 \%$ de $\mathrm{K}$ e $\mathrm{Fe}$. Na avaliação seguinte, o maior número de folhas emitidas foi obtido através do cultivo em concentração de $150 \%$ de $\mathrm{Fe}$, seguido das concentrações de 150,50 e $200 \%$ de K.

O diâmetro caulinar é uma característica importante em análises de crescimento não destrutivo e, quando as plantas foram cultivadas em solução nutritiva com concentração de $150 \%$ de K e $\mathrm{Fe}$, sua taxa de crescimento foi maior nesses tratamentos, possivelmente, devido as funções desses nutrientes nas plantas. Estudando o crescimento e a diagnose de deficiências nutricionais em fisalis, Moschini et al. (2018) aferiram que o Fe é um importante nutriente para o crescimento e o desenvolvimento vegetal das plantas, pois na omissão desse nutriente em solução nutritiva foi possível observar menores valores em relação ao diâmetro caulinar da fisalis. Outro nutriente que é indispensável para a cultura da fisalis é o K que está associado a formação e o tamanho dos frutos (FISCHER, MIRANDA, 2012). Em um estudo avaliando a deficiência induzida de nitrogênio, fósforo e potássio em mudas de lulo (Solanum quitoense), Machado et al. (2016) aferiram que a omissão de $\mathrm{K}$ na solução nutritiva resultou em diminuição do diâmetro caulinar e outros parâmetros de crescimento das plantas de lulo.

A altura da planta é outro atributo morfológico de importância para analisar o desenvolvimento vegetal, e o excesso de um determinado nutriente no meio de cultivo pode suspender o crescimento, como pode ser observado para as plantas cultivadas em solução nutritiva com concentração de $200 \%$ de Fe. $\mathrm{Na}$ literatura não há informações a respeito da toxicidade desse nutriente sobre as plantas de fisalis. Entretanto, o excesso de Fe no morangueiro provoca uma diminuição na atividade da enzima quelato de ferro redutase (QF-R), que age como um mecanismo de defesa contra a toxicidade desse nutriente. Apesar da planta conseguir controlar a entrada excessiva de $\mathrm{Fe}$, pode ocorrer consequências morfológicas, como a limitação do crescimento e o bronzeamento das 
folhas (MARTINS, 2017). Acredita-se que o Fe em níveis adequados no meio de cultivo, seja extremamente importante para a fisalis, pois os níveis desse nutriente na composição mineral dos frutos são muito elevados (MAMEDOV et al., 2017; MOKHTAR et al., 2018).

O número de folhas emitidas foi maior nas plantas cultivadas em solução nutritiva com concentração de $150 \%$ de Fe em ambas avaliações e em concentração de 50 e $150 \%$ de K na segunda avaliação. $\mathrm{O}$ maior crescimento das plantas em relação ao número de folhas emitidas pode estar associado ao fato de que o Fe é um nutriente essencial às plantas e, a sua ausência e/ou toxicidade pode limitar a produção de biomassa e a qualidade dos produtos vegetais, pois altera o aparato fotossintético e promove sua remodelação (BRIAT et al., 2015). Enquanto o $\mathrm{K}$ relaciona-se com a regulação do potencial osmótico e turgor das células vegetais e na ativação de enzimas associadas à fotossíntese e a respiração, sendo indispensável seu suprimento às plantas por acarretar em redução do crescimento vegetal (FAGERIA, 2015).

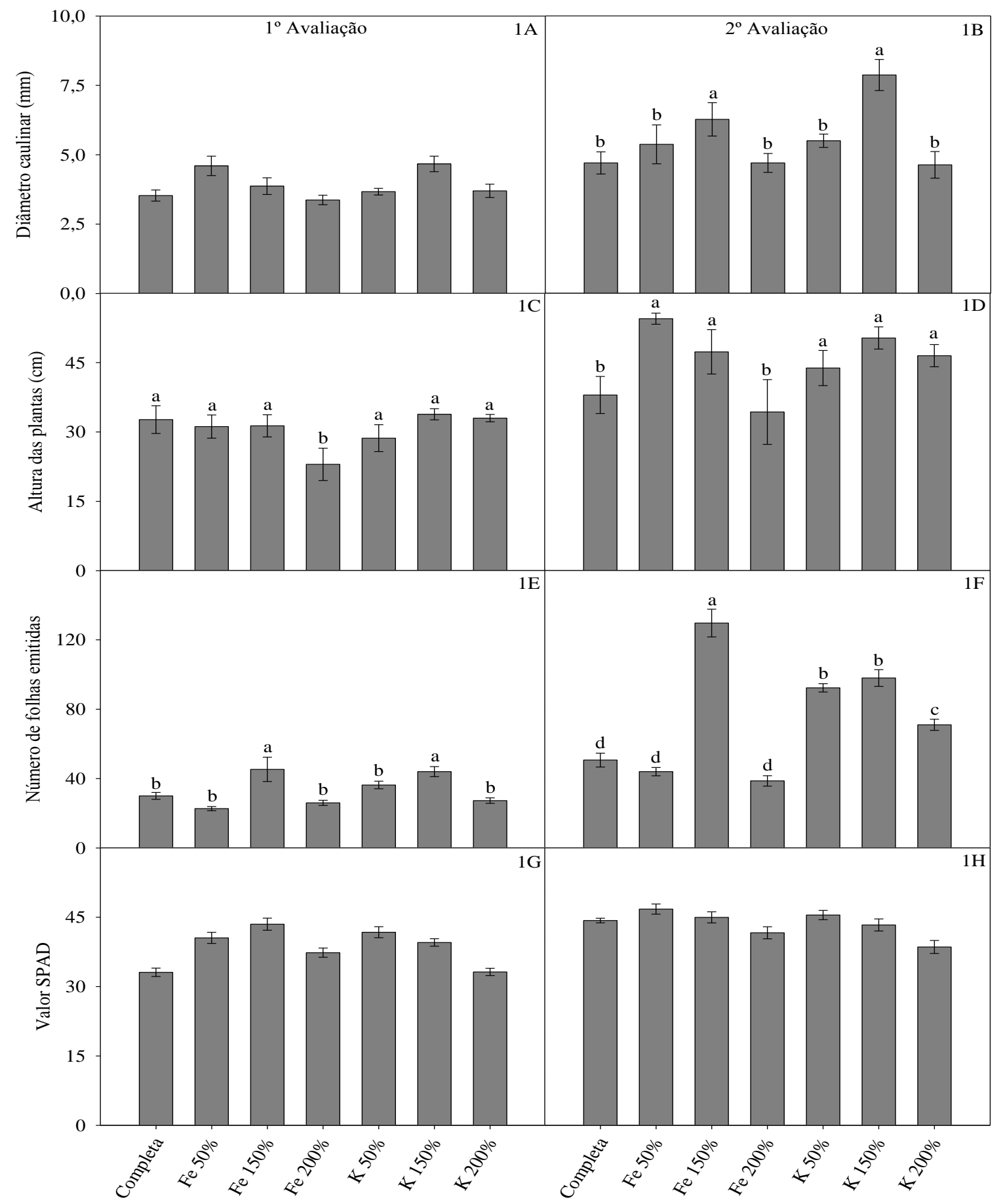

Figura 1 - Média do diâmetro caulinar (mm) (1A, 1B), altura das plantas (cm) (1C, 1D), número de folhas emitidas (1E, 1F) e valor SPAD $(1 \mathrm{G}, 1 \mathrm{H})$ de mudas de fisalis cultivadas em solução nutritiva em diferentes concentrações de K e Fe em duas avaliações. 
Sabidamente, a concentração de clorofila correlaciona-se positivamente com a concentração de $\mathrm{N}$ na planta e, consequentemente, com a produtividade das culturas. Dessa forma, a falta de resposta para os valores SPAD neste estudo é justificado pela concentração de $\mathrm{N}$ na solução nutritiva que foi igual para todos os tratamentos. Porém, os dados contradizem com a literatura em relação ao $\mathrm{Fe}$, pois esse nutriente atua no mecanismo de formação da clorofila, e em casos de deficiência, a concentração de clorofila pode ser reduzida (BASHIR et al., 2015) e, consequentemente, o valor SPAD pode ser afetado.

É possível verificar que o $\mathrm{K}$ e o $\mathrm{Fe}$ são nutrientes que podem limitar o crescimento e o desenvolvimento da fisalis, portanto esse fato ressalta a importância da prática do uso desses nutrientes durante a adubação, pois a ausência desses nutrientes poderia comprometer a produtividade da fisalis.

\section{Produção de biomassa das plantas}

Os dados de produção de massa seca e a relação $\mathrm{R} / \mathrm{PA}$, tendo o tratamento com solução nutritiva completa como referência estão apresentados na Figura 2. A partir da análise de variância foi possível observar diferenças $(p \leq 0,05)$ entre os tratamentos na produção de massa seca total da fisalis. E apesar da grande variação da relação $\mathrm{R} / \mathrm{PA}$ entre os tratamentos, não houve diferença significativa entre os valores obtidos em ambas avaliações realizadas.

A massa seca é um importante atributo de crescimento e o mais utilizado e significativo, pois determina o aumento de massa acumulada na formação de um órgão ou da planta toda sem levar em consideração o conteúdo em água. Assim, os maiores valores médios de massa seca total foram obtidos pelas plantas cultivadas em concentração de $150 \%$ de $\mathrm{Fe}$ em ambas as avalições, enquanto os menores valores médios foram atribuídos às plantas cultivadas em concentração de $50 \%$ de $\mathrm{Fe}$ na segunda avaliação, representando um valor $34 \%$ inferior ao tratamento com solução completa. É possível observar, também, que os dados de massa seca total das plantas de fisalis em ambas avaliações apresentaram padrões de respostas similares com os dados de número de folhas emitidas. Com isso, o número de folhas emitidas pode ter sido o parâmetro de crescimento que mais influenciou a produção de biomassa nas plantas.

$\mathrm{O}$ menor crescimento das plantas cultivadas em concentração de $50 \%$ de $\mathrm{Fe}$ foi semelhante aos resultados obtidos por Lee et al. (2016) que observaram, em morangueiro, que plantas que crescem sem $\mathrm{Fe}$ apresentam menor produção de biomassa, esse fato está associado a desequilíbrios nutricionais e/ou estresse oxidativo. Esses resultados são reforçados pelo estudo realizado por Martins (2017), estudando a dinâmica do Fe em morangueiro aferiu que a ausência desse nutriente na solução nutritiva provocou sintomas de clorose férrica e diminuição dos parâmetros na produção de biomassa. Outros estudos envolvendo o $\mathrm{Fe}$ na cultura do morangueiro mostram que sua aplicação é necessária para aumentar o rendimento e outros parâmetros da qualidade dos frutos, além de influenciar grandemente os parâmetros de crescimento das plantas (HOSSEINI, BAHADORI, 2017; MOZAFARI et al., 2017).

Embora a massa seca das plantas cultivadas nas diversas concentrações de $\mathrm{K}$ não tenha diferido entre si e ao tratamento com solução completa, o K parece ser um nutriente indispensável para o bom rendimento de frutos da fisalis. Martinez et al. (2008) cultivando fisalis em vasos de $25 \mathrm{~kg}$ preenchidos com areia lavada, observaram que o rendimento (número e peso fresco dos frutos) foi consideravelmente menor pela omissão de $\mathrm{K}$ no meio de cultivo. Em um estudo avaliando a fertilização mineral e orgânica em duas espécies de fisalis, foi possível observar que o aumento da produção de frutos foi maior nas plantas com fertilização orgânica, devido a disponibilidade de nutrientes de forma equilibrada, disponibilizando quantidades suficientes de $\mathrm{K}$ de forma gradativa, suprindo satisfatoriamente a demanda da planta (ARIATI et al., 2017). Além de ser um nutriente indispensável para o rendimento dos frutos, a composição mineral dos frutos da fisalis também é muito rica em K (MUSINGUZI et al., 2007), justificando a sua importância.

Fica evidente que as concentrações de $\mathrm{Fe}$ na solução nutritiva foram as que mais limitaram a produção de biomassa seca nessa espécie. O Fe é essencial e a sua ausência pode prejudicar no crescimento e o desenvolvimento das plantas (BRIAT et al., 2015), essa essencialidade está ligada ao processo fotossintético, biossíntese da clorofila, respiração e a diversas enzimas que participam de reações de oxirredução no metabolismo vegetal (JEONG, CONNOLLY, 2009).

Através da relação R/PA é possível analisar o crescimento do sistema radicular em relação ao crescimento da parte aérea. Porém, para que essa relação possa ser estimada, o sistema radicular deve ser considerado como um importante componente da planta (MAGALHÃES, 1979). Os valores da relação R/PA variaram entre 0,18 a 0,28 e 0,15 a 0,26 , respectivamente na primeira e segunda avaliação realizada, sendo que não foi observado diferença significativa entre os tratamentos. A relação R/PA é um atributo muito plástico e responsivo aos 
tratamentos que afetam a raiz, portanto, foi possível observar que a fisalis respondeu de modo similar em relação às concentrações de $\mathrm{K}$ e Fe quando avaliado esse parâmetro de crescimento.

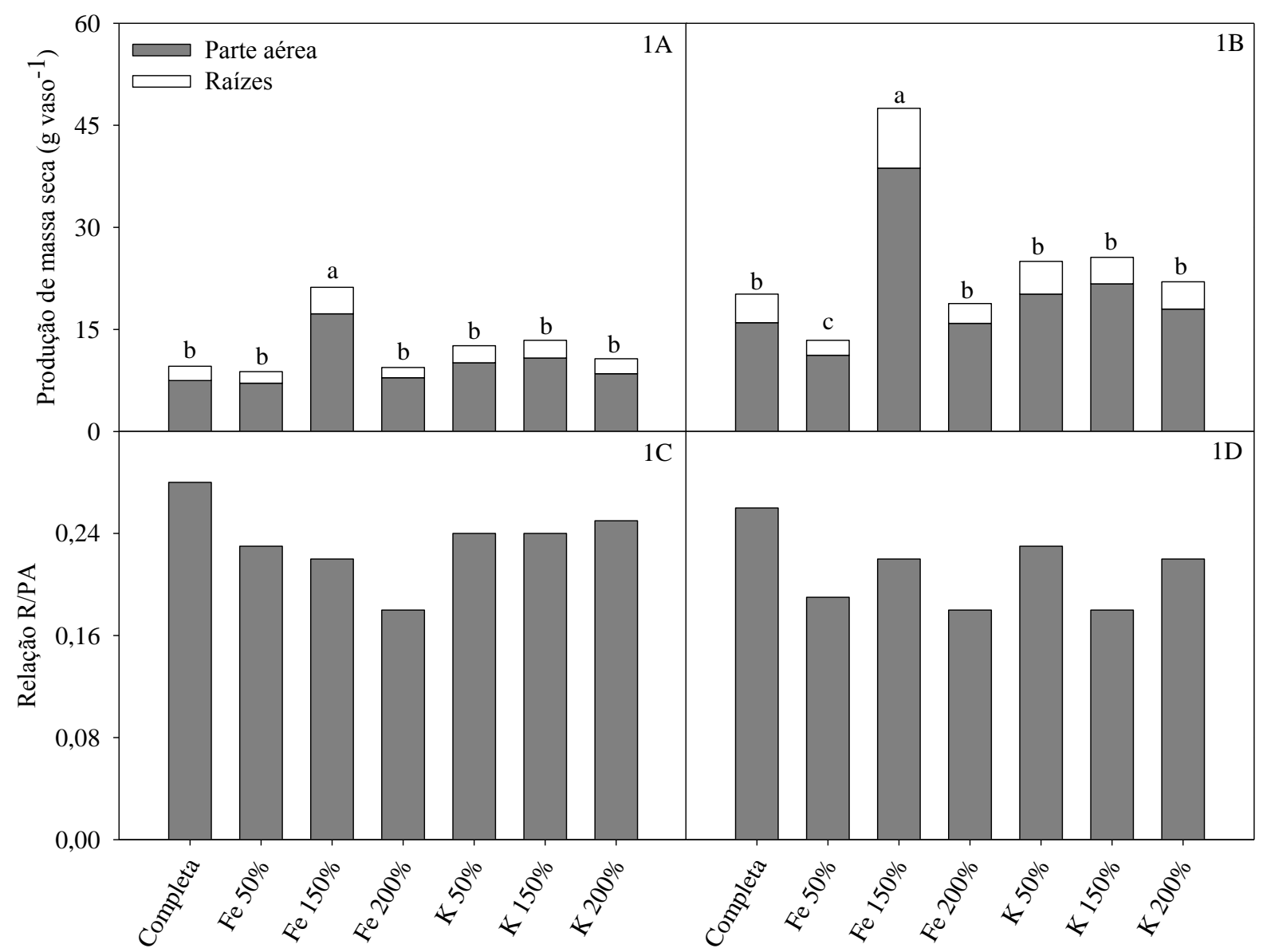

Figura 2 - Média da produção de massa seca da parte aérea e raízes $\left(\mathrm{g}\right.$ vaso $\left.^{-1}\right)$ (1A, 1B) e relação R/PA (1C, 1D) de mudas de fisalis cultivadas em solução nutritiva em diferentes concentrações de $\mathrm{K}$ e Fe em duas avaliações.

Com o intuito de avaliar o estado nutricional por meio da diagnose visual foi fotografada todas as plantas ao final do período experimental (40 dias), porém apenas as plantas cultivadas em solução com concentração de $50 \%$ de $\mathrm{Fe}$ apresentaram sintomas de deficiência nutricional. Dessa forma, foi observado redução do porte vegetal tanto da parte aérea (Figura 1 e 2) quanto do sistema radicular (Figura 3) em relação ao tratamento com solução completa. Primeiramente, verificou-se um tom mais

\section{Diagnose do estado nutricional}

arelado sobre a superfície das folhas com clorose internerval nas folhas mais novas, formando um reticulado fino. Embora os valores SPAD não tenham apresentado diferenças significativas (Figura $1 \mathrm{G}$ e $1 \mathrm{H}$ ), é provável que o amarelecimento das folhas pode estar associado ao mecanismo de formação da clorofila (BASHIR et al., 2015). Esses mesmos sintomas foram observados por Souza et al. (2015) em amoreira-preta e por Moschini et al. (2018) em fisalis. 


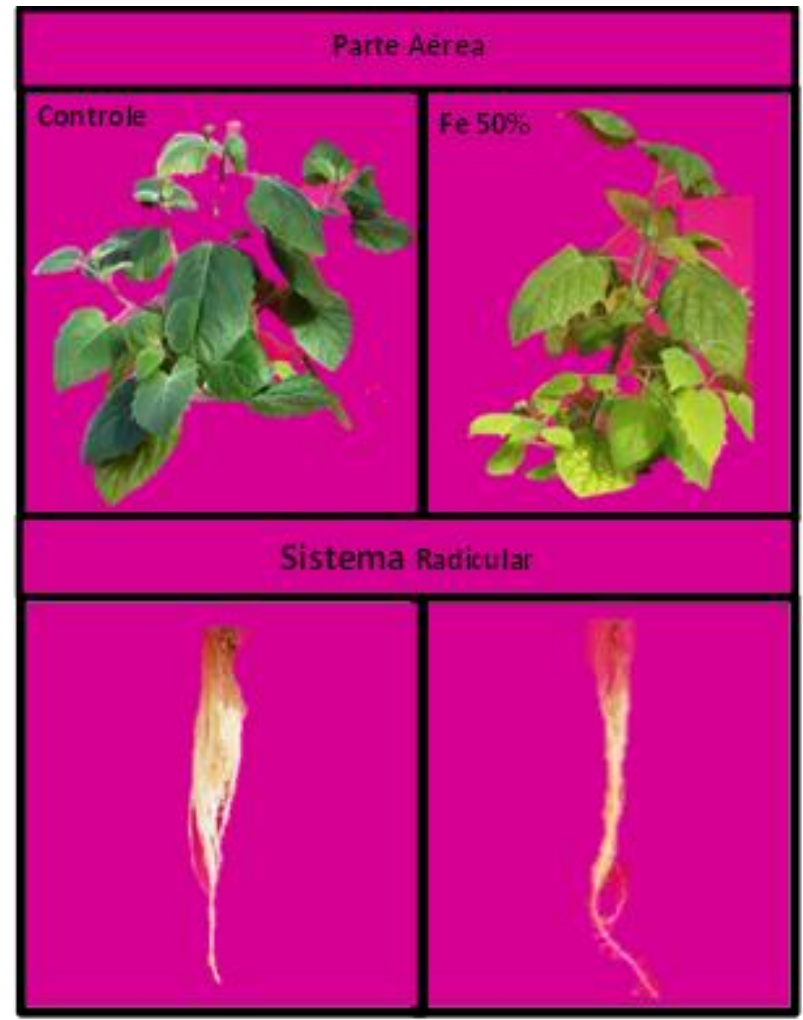

Figura 3 - Sintomatologia da deficiência nutricional na parte aérea e sistema radicular de mudas de fisalis cultivadas em solução nutritiva completa e com concentração de $50 \%$ de Fe.

Os sintomas de deficiência são manifestações exteriores de eventos bioquímicos, que ocorrem em nível molecular e celular, nos tecidos vegetais (SILVA et al., 2009). A manifestação de sintomas visíveis devido à falta de um nutriente é singular para cada nutriente. E o motivo pelo qual o sintoma é típico, deve-se ao fato de que um dado nutriente exerce sempre as mesmas funções em qualquer espécie de planta.

De acordo com Raij (1991) e Faquin (2002), o transporte de Fe se dá pela corrente transpiratória e no exsudado do xilema, predominantemente na forma de quelato do ácido cítrico. Na planta em desenvolvimento e na adulta, entretanto, não ocorre a redistribuição do $\mathrm{Fe}$ e, como consequência, a lâmina foliar amarelece, enquanto as nervuras podem permanecerem verdes durante algum tempo, destacando-se como um reticulado fino, como observado nesse estudo. Com a evolução da deficiência ou em casos extremos, as folhas podem sofrer um branqueamento.

Para as demais concentrações de $\mathrm{K}$ e Fe não foi possível observar diferenças visuais entre as plantas cultivadas, embora os parâmetros de crescimento e a produção de biomassa tenham se diferenciado.

\section{CONCLUSÕES}

1. As concentrações de Fe apresentaram-se como um fator limitante para o desenvolvimento vegetativo inicial das mudas de fisalis.
2. O crescimento e o desenvolvimento da fisalis foi maior nas plantas cultivadas em solução com concentração de $150 \%$ de Fe.

3. As concentrações de $\mathrm{K}$ não ocasionaram efeito sobre a altura das plantas, valor SPAD, produção de biomassa seca e relação R/PA.

\section{AGRADECIMENTO}

Ao Conselho Nacional de Desenvolvimento Científico e Tecnológico (CNPq), à Coordenação de Aperfeiçoamento de Pessoal de Nível Superior (CAPES) e à Fundação de Amparo à Pesquisa do Estado de Minas Gerais (FAPEMIG) por financiarem as bolsas de pesquisa aos autores; e ao Departamento de Ciência do Solo (DCS) da Universidade Federal de Lavras (UFLA) pela oportunidade de desenvolver esse estudo.

\section{REFERÊNCIAS}

ARIATI, A. A., OLIVEIRA, M. C., PERDA, E. M. S., GOMES, I., PACHECO, V., NEGRI, R. C. Mineral and organic fertilizer in two Physalis species. African Journal of agricultural research, v. 12, n. 2, p. 104-110, 2017.

BARROSO, D. G., FIGUEIREDO, F. A. M. M. A., PEREIRA, R. C., MENDONÇA, A. V. T., SILVA, L. C. Diagnóstico de deficiências de macronutrientes em mudas de teca. Revista Árvore, v. 29, n. 5, p. 671-679, 2005. 
BASHIR, H., QURESHI, M. I., IBRAHIM, M. M., IQBAL, M. Cloroplastos e fotossistemas: impacto do cádmio e deficiência de ferro. Photosynthetica, v. 53, n. 3, p. 321-335, 2015.

BRIAT, J. F., DUBOS, C., GAYMARD, F. Iron nutrition, biomass production, and plant product quality. Trends in Plant Science, v. 20, n. 1, p. 33-40, 2015.

BRYSON, G. M., MILLS, H. A. Plant analysis handbook IV: A practical sampling, preparation, analysis and interpretation guide. 4. ed. Athens: Micro Macro Publishing, 2015.

BENINCASA, M. M. P. Análise de crescimento de plantas: noções básicas. Jaboticabal-SP: FUNEP, 2003, 41p.

FAGERIA, N. K. Potassium. In: BARKER, A. V., PILBEAM, D. J. Handbook of plant nutrition. 2. ed. Boca Raton: CRC Press. 2015. p.127-164.

FAQUIN, V. Diagnose do estado nutricional das plantas. Lavras-MG: FAEPE/UFLA, 2002, 77p.

FERREIRA, D. F. SISVAR: um programa para análises e ensino de estatística. Revista Científica Symposium, v. 6, n. 2, p. 36-41, 2008.

FISCHER, G., MIRANDA, D. Uchuva (Physalis peruviana L.). In: FISCHER, G. Manual para o cultivo de árvores frutíferas nos trópicos. Bogotá: Produmedios. 2012. p.851-873.

HOAGLAND, D. R., ARNON, D. L. The water culture methods for growing plants without soil. Berkeley: California Agriculture Experiment Station, 1950, 32p.

HOSSEINI, Y., BAHADORI, M. Efeito da fonte, quantidade e método de aplicação de ferro na quantidade, qualidade e taxa de rentabilidade do morango (Fragaria $\times$ ananassa Duch, cv. Selva). Revista de Ciência e Tecnologia de Cultura de Efeito Estufa, v. 7, n. 28, p. 149-160, 2017.

IANCKIEVICZL, A., TAKASHI, H. W., FREGONEZI, G. A. F., RODINI, F. K. Produção e desenvolvimento da cultura de Physalis L. submetida a diferentes níveis de condutividade elétrica da solução nutritiva. Ciência Rural, v. 43, n. 3, p. 438-444, 2013.

JEONG, J., CONNOLLY, E. L. Iron uptake mechanisms in plants: Functions of the FRO family of ferric reductases. Plant Science, v. 176, n. 6, p. 709-714, 2009.

MACHADO, L. M., AGUILAR, A. S., OLIVEIRA, R. C., LIMA, D. T. Deficiência induzida de nitrogênio, fósforo e potássio em mudas de lulo. Scientia Agraria Paranaensis, v. 15, n. 1, p. 76-81, 2016.

MAGALHÃES, A. C. N. Análise quantitativa do crescimento. In: FERRI, M. G. Fisiologia vegetal. 1. ed. São Paulo-SP: USP. 1979. p.331-350.
MALAVOLTA, E., VITTI, G. C., OLIVEIRA, S. A. Avaliação do estado nutricional das plantas: princípios e aplicações. Piracicaba-SP: POTAFOS, 1997, 319p.

MAMEDOV, M. I., ENGALYCHEV, M. R., JOSS, A. E. Morpho-biological properties and biochemical composition of physalis (Physalis pubescens L.) fruits in a temperate climate. Vegetable crops of Russia, v. 2, n. 35, p. 76-80, 2017.

MARTÍNEZ, F. E., SARMIENTO, J., FISCHER, G., JIMÉNEZ, F. Efecto de la deficiencia de N, P, K, Ca, Mg y $\mathrm{B}$ en componentes de producción y calidad de la uchuva (Physalis peruviana L.). Agronomia Colombiana, v. 26, n. 3, p. 389-398, 2008.

MARTINS, M. L. C. F. Estudo da dinâmica do ferro em morangueiro (Fragaria $x$ ananassa Dutch) cv. Diamante. 2017. 59f. Dissertação (Mestrado em Engenharia Agronómica) - Universidade de Lisboa, Portugal.

MOKHTAR, S. M., SWAILAM, H. M., EMBABY, H. Physicochemical Properties, Nutritional Value and Techno-funnctional Properties of Goldenberry (Physalis peruviana) Waste powder Concise title: Composition of goldenberry juice waste. Food Chemistry, v. 248, p. 1-7, 2018.

MOSCHINI, B. P.; COELHO, V. A. T.; PECHE, P. M.; SOUZA, F. B. M.; COUTINHO, G.; BARBOSA, C. M. A.; FREIRE, A. I. Crescimento e diagnose de deficiências nutricionais em Physalis peruviana L. Revista Agropecuária Técnica, v. 38, n. 4, p. 169-176, 2018.

MOZAFARI, A. A., HAVAS, F., GHADERI, N. Application of iron nanoparticles and salicylic acid in in vitro culture of strawberries (Fragaria $\times$ ananassa Duch.) to cope with drought stress. Plant Cell, Tissue and Organ Culture, v. 132, n. 3, p. 511-523, 2017.

MUNIZ, J., KRETZSCHMAR, A. A., RUFATO, L., PELIZZA, T. R., RUFATO, A. R., MACEDO, T. A. General aspects of physalis cultivation. Ciência Rural, v. 44, n. 6, p. 964-970, 2014

MUNIZ, J., MARCHI, T., COLDEBELlA, M. C., RUFATO, L., KRETZSCHMA, A. A. Crescimento vegetativo e potencial produtivo de fisalis. Revista de Ciências Agroveterinárias, v. 14, n. 1, p. 15-23, 2015.

MUSINGUZI, E., KIKAFUNDA, J., KIREMIRE, B. Promoting indigenous wild edible fruits to complement roots and tuber crops in alleviating vitamin A deficiencies in Uganda. In: Proceedings of the 13th ISTRC Symposium. Dar Salam, 2007, p.763-769.

PEREIRA, I. S. Adubação de pré-plantio no crescimento, produção e qualidade da amoreira-preta (Rubus sp.). 2008. 149p. Dissertação (Mestrado em Agronomia) - Universidade Federal de Pelotas, Pelotas. 
PONCE, O. V., MARTINEZ, J. S., TAVARES, M. P. Z., MARES, L. E. V. Traditional management of a smallscale crop of Physalis angulata in Western Mexico. Genetic Resources and Crop Evolution, v. 63, n. 8, p. 1383-1395, 2016.

RAIJ, B. Van. Fertilidade do solo e adubação. Piracicaba-SP: POTAFOS, 1991, 343p.

RUFATO, L., MUNIZ, J., KRETZSCHMAR, A. A., RUFATO, A. R., GATIBONI, L. C. Aspectos técnicos da cultura da fisalis. Informe Agropecuário, v. 33, p. 69-83, 2012.

SALGADO, E. R., ARANA, G. V. Physalis angulata L. (Bolsa Mullaca): A Review of its Traditional Uses, Chemistry and Pharmacology. Boletín Latinoamericano y del Caribe de Plantas Medicinales y Aromáticas, v. 12, n. 5, p. 431-445, 2013.
SILVA, E. B., TANURE, L. P. P., SANTOS, S. R., RESENDE JÚNIOR, P. S. Sintomas visuais de deficiências nutricionais em pinhão-manso. Pesquisa Agropecuária Brasileira, v. 44, n. 4, p. 392-397, 2009.

SOUZA, F. B. M., PIO, R., COELHO, V. A. T., RODAS, C. L., SILVA, I. P. Sintomas visuais de deficiência de macronutrientes, boro e ferro e composição mineral de amoreira-preta. Pesquisa Agropecuária Tropical, v. 45, n. 2, p. 241-248, 2015.

THOMÉ, M., OSAKI, F. Adubação de nitrogênio, fósforo e potássio no rendimento de Physalis spp. Revista Acadêmica: Ciências Agrárias e Ambientais, v. 8, n. 1, p. 11-18, 2010. 